\title{
Effect of Job Satisfaction on Empathic Skills among Oncology Nurses at Kirkuk City
}

\author{
Dhiaa Alrahman Hussein ${ }^{1}$, Waleed Ibrahim Saad ${ }^{1}$ \\ ${ }^{I}$ Master Degree in Nursing / University of Kirkuk / College of Nursing / Iraq
}

\begin{abstract}
Background: Nursing care delivered to the patients by using physical, mental, social, spiritual and emotional skills. Increasing the level of job satisfaction can promote the level of empathy skills. Thus improving nursing care quality

Objectives: The aims of the study were to assess of the level of job satisfaction and the level of empathy skills, as well as to assess the effect of job satisfaction on empathy skills among oncology nurses.

Methodology: A correlational study (quantitative design) was carried out at oncology and hematology disease center at Kirkuk city for oncology nurses from first of February, 2020, up to the first of October, 2020. A purposive sampling (non- probability) of (56) oncology nursesboth males and females was selected. The instrument used in the study was designed by the researchers according to the previous literaturesto achieve the purposes of the study. The instrument of the study was consisting of fourparts: thefirst part was the demographical data of the participants, the second part was the Occupational data. The third Part was the Job Satisfaction Scale. And the fourth part was the nurses Empathy skills level. The data collection process wereutilized by using self-report technique. The data analysis were by using the descriptive statistical analysis (frequency and percentage) and inferential statistical analysis (Pearson correlation).
\end{abstract}

Results: The results of the study demonstrate that $(80 \%)$ of the nurses were dissatisfied regarding nursing job,also the results demonstrate that (64\%) of the participants having moderate empathy skill level, (32\%) of the participants having low empathy skills level.

Conclusions: The study concluded that job satisfaction have clear effect on empathy skills among oncology nurses.

Keywords: Effect, Job satisfaction, empathic skills, oncology nurses.

\section{Introduction}

Empathy is a broad and complex concept that the person feel of others. In the nursing profession use empathy is important and very necessary for the delivery of integrated care for patients. Empathy is a multi-dimensional concept with cognitive matter as well as emotive matter. Cognitive empathy is an

\footnotetext{
Corresponding Author:

Dhiaa Alrahman Hussein

M.Sc. Science in Nursing/University of Kirkuk/College of Nursing/Iraq

e-mail: dhiaa_h33@uokirkuk.edu.iq
}

individual's abilities to understand the perspective of theothers about their conditions and emotive empathy is an individual's issues for the feelings of the others ${ }^{1}$. Oncology and intensive care units are distinct areas in terms of interaction and communication with the patients demonstrate passion and empathy skills. To improve patients care, nurses should develop empathy skills. Nurses with enhanced empathic abilities can understand the patient needs.There are general agreementsthat the positive correlation between empathy, patients' outcomes and clinical competence; there are still some conflict in the Relationship between empathy and nurses' well-being ${ }^{2}$. Understanding patients' needs, feelings, and their situation is the essential nursing tasks and empathy is the basis for this understanding. Therefore, highlight 
to this concept, from the perspective of medical and nursing staff is important ${ }^{3}$.

\section{Objective of the study:}

1. To assess demographic and occupational data of the study sample

2. To assess job satisfaction level among oncology nurses

3. To assess empathy skills level among oncology nurses

4. To find correlation between job satisfaction and empathy skills

\section{Methodology}

A correlational study (quantitative design) was conductedin oncology and hematology disease center at Kirkuk City for oncology nurses from first of February, 2020, up to the first of October, 2020. To assess the effect of Job Satisfaction on Empathy Skills among oncology nurses at Kirkuk City. A non-probability (purposive sampling) of 56 nursing staff working in oncology and hematology disease center both males and females was selected. The instrument of the study was designed by the researchers according to the previous literaturesto achieve the purposes of the study. The instrument of the studywas consisting of four parts. The first part was the demographical data of the participants consist of (3) items, the second part was the Occupational data consist of (3) items. The third part was the Job Satisfaction Scaleconsisting of (15) items. And the fourth part was the Nurses Empathy skills levelconsisting of (20) items. The data collection process were done by the use of self-reporting technique from the period $1^{\text {st }}$ May 2020 to $1^{\text {st }}$ June 2020 . The informed consent was obtained from the nurses to participate in the current study. The data analysis were done by using the Statistical Package for Social Science (SPSS). The data analysis done by using the descriptive statistical analysis (frequency and percentage) and inferential statistical analysis (Pearson correlation).to find the effect of Job Satisfaction on Empathy Skills.

\section{Results}

Table (1): Occupational data of the samples $(n=56)$

\begin{tabular}{|c|c|c|c|}
\hline No. & Variables & $\mathbf{F}$ & $\%$ \\
\hline \multirow{5}{*}{1} & \multicolumn{3}{|c|}{ Salary (monthly income) in Iraqi Dinar } \\
\hline & less than 500000 IQD & 12 & 21.4 \\
\hline & 500000- 1 million IQD & 40 & 71.4 \\
\hline & more than 1 million IQD & 4 & 7.2 \\
\hline & Total & 56 & 100 \\
\hline \multirow{4}{*}{2} & \multicolumn{3}{|c|}{ Number of working hours per week } \\
\hline & 30 - 40 hours/week & 34 & 60.7 \\
\hline & More than 40 hours/week & 22 & 39.3 \\
\hline & Total & 56 & 100 \\
\hline \multirow{5}{*}{3} & \multicolumn{3}{|l|}{ Type of working shift } \\
\hline & Day shift & 20 & 35.7 \\
\hline & Night shift & 10 & 17.9 \\
\hline & Day and Night shift & 26 & 46.4 \\
\hline & Total & 56 & 100 \\
\hline
\end{tabular}

This table reveals that $(71.4 \%)$ were 500000 1 million IQD, (60.7\%) of the participant working between 30-40 hours/week, most study sample having day and night shift, and most participant havn't other work and havn't job related disease. 


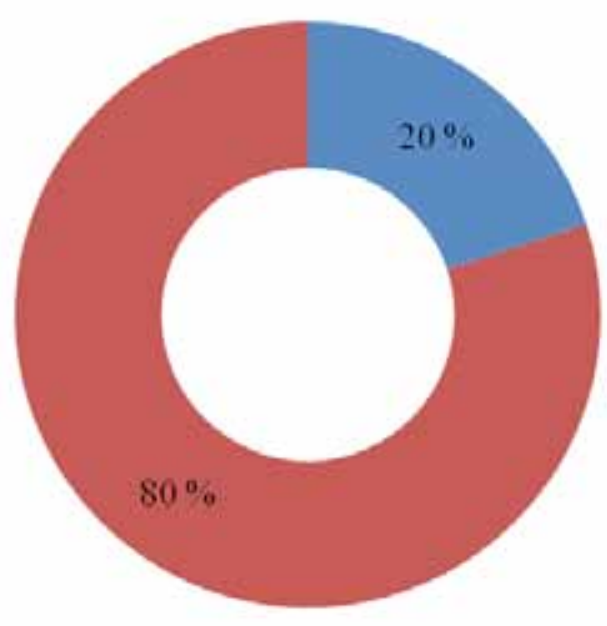

Satisfied

Dissatisfied

Figure (1): Level of job satisfaction among oncology nurses. The figure revealed that the majority of the participant were not satisfied about their job>. $(20 \%)$ were satisfied.

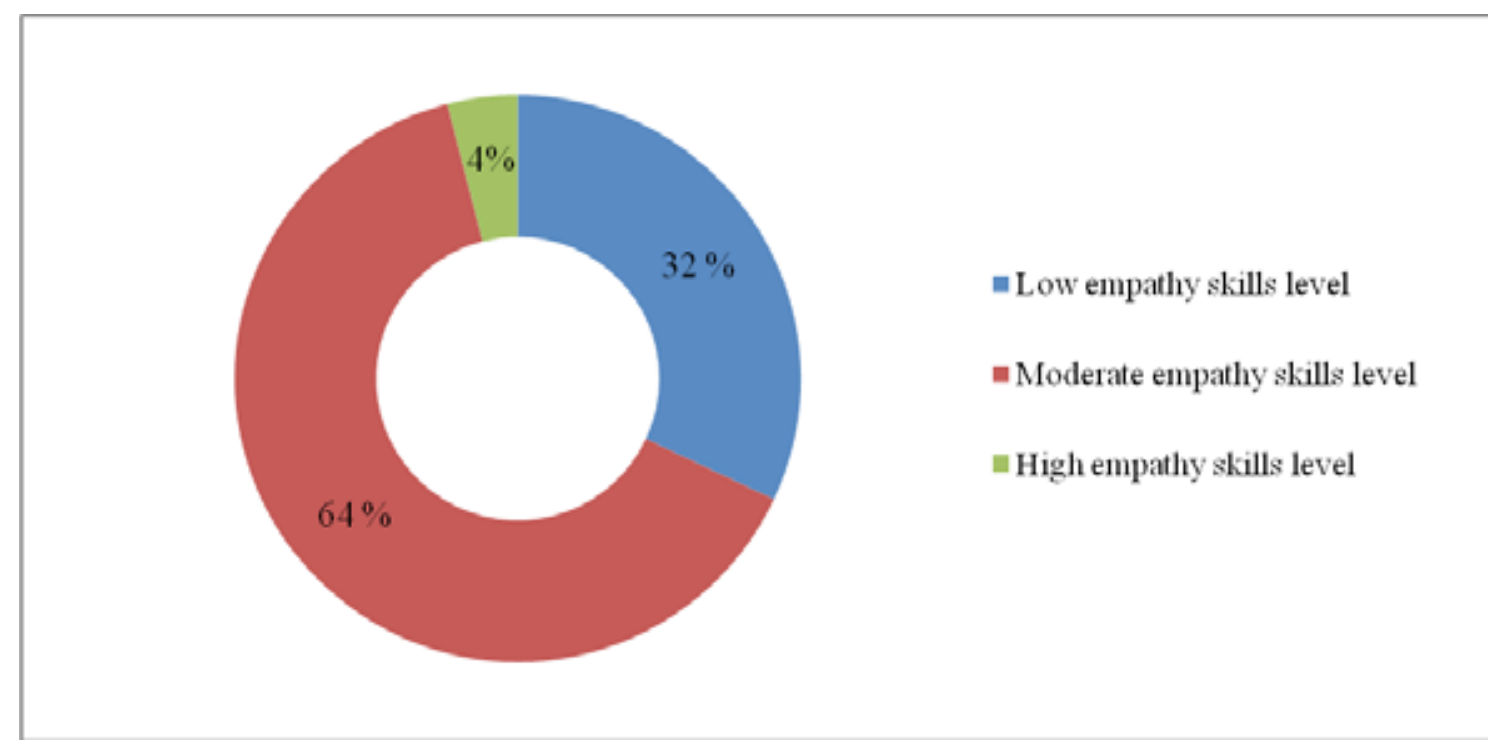

Figure (2): Level of empathy skills among oncology nurses. The figure revealed that most participant having Moderate empathy skills, (32\%) of the participant with Low empathy skills. And (4\%) were High empathy skills.

Table (2): The correlation between Job satisfaction and Empathy skills

\begin{tabular}{|l|l|c|c|}
\hline \multicolumn{2}{|c|}{} & Job Satisfaction & Empathy Level \\
\hline \multirow{4}{*}{ Job satisfaction } & Pearson Correlation & 1 & $.701^{* *}$ \\
\cline { 2 - 4 } & Sig. (2-tailed) & 56 & .000 \\
\cline { 2 - 4 } & $\mathrm{N}$ & $.701^{* *}$ & 56 \\
\hline \multirow{3}{*}{ Empathy level } & Pearson Correlation & .000 & 1 \\
\cline { 2 - 4 } & Sig. (2-tailed) & 56 & \multirow{2}{*}{56} \\
\cline { 2 - 4 } & $\mathrm{N}$ & & \\
\cline { 2 - 4 }
\end{tabular}

**Correlation is significant at 0.01 level $(2$ - tailed $)$

This table shows the Job satisfaction have an obvious effect on Empathy skills 


\section{Discussion}

Empathy skills are essentialwhencare of patients, especially in oncology setting and critical cases ${ }^{4}$. Nursing profession includes the human, emotional, mental and social aspect when providing nursing care to hospitalized patients. Nursing services are not only limited to the physical care, but also the nursesprovides physical, psychosocial, and emotional care for patients, especially critically ill patients and cancerous patients. According to Fan et al 2017 which state that psychosocial support included not only disease events but also emotional and supporting family ${ }^{5}$. The nursing profession is affected by several factors, including professional and administrative factors that affect the provision of nursing services by nurses. The study aims to assess the effect of job satisfaction on empathy skills among oncology nurses.

The results demonstrate that most of the nurses were dissatisfied about nursing profession and with the nature of work with other health personnel. may be several reasons leading to dissatisfaction, including the inadequate monthly income compared to several countries and neighboring countries, and there are also professional and administrative reasons that determine the independency of the nurse at work, the nature of the work, and the lack of material and moral rewards for the nursing staff. According to the level of empathy skills of the oncology nurses, the results revealed that most of the nurses had moderate level of empathy skill, and this resulted from job dissatisfaction with the nursing profession. This results is similar with the study conducted on nursing students which indicate that the Participants having moderate degree of empathy skills level $^{6}$. According to Perez et al, Empathy Levels are reflected more in women than in men in general ${ }^{7}$. The study of Elayyan et al concluded that empathetic of healthcare workersresponses to patients are correlated and connected to a well-resourced, collegial, professional organizational environment that builds empathy for nurses and doctors ${ }^{8}$. The results of the current study also revealed whenever level of job satisfaction is low, it may lead to less interest in patients and thus less empathy skills of the nursing staff, meaning that job satisfaction has a clear effect on the empathy skills of the oncology nurses. As stated by Buyuk et al that the nurses who chose nursing Willingly had a higher level of empathy skills than those whose families chose nursing for them ${ }^{9}$. Karem et al 2019 indicated that there is a significant effect of Job satisfaction on nurses' skills. Study of
Karem et al 2019 indicates if the nurses have high beliefs, and support the current value by the hospital, have the readiness to provide much effort for the hospital, and working with a high level of commitment ${ }^{10}$.

\section{Conclusions}

Job satisfaction have an obvious effect on empathy skills, Most nurses working 30 -40 hour/week, and most of them working in day and night shift, The majority of the participant were dissatisfied about nursing job, Most participant having Moderate empathy skills.

Acknowledgement: The authors would like to acknowledge the nursing staff who took part in this study and to Kirkuk health directorate and Deanship of Nursing College at University of Kirkuk for their endless assistance.

Financial Disclosure: There is no financial disclosure.

Conflict of Interest: None to declare.

Ethical Clearance: Official approval was obtained from directorate of health in Kirkuk city to conduct the study and data collection. Informed consent was obtained from the oncology nurses.

\section{Reference}

1. West, C., Huschka, M., Novotny, P., Sloan, J., Kolars, J., Habermann, T., \& Shanafelt, T. Association of perceived medical errors with resident distress and empathy: a prospective longitudinal study. Jama, 2006,296(9), 1071-1078.

2. Yu, J. and Kirk, M. Measurement of empathy in nursing research: systematic review. Journal of Advanced Nursing. 2008; 64(5):440-454. PMid:19146512 http://dx.doi.org/10.1111 /j.1365-2648.2008.04831.

3. Zeighami R, Rafiie F, Parvizi S. Concept analysis of empathy in nursing. Journal of Qualitative Research in Health Sciences 2012; 1 (1), 27-33.

4. Alkan A., The effects of Nurses' Empathy Skills on Attitudes towards Patients with Cancer, Journal of Clinical and Experimental Investigations, 2017, vol. 8 (2), 69-73.

5. Fan S. et al, Psychosocial Care Provided by Physicians and Nurses in Palliative Care: A Mixed Method Study, Journal of Pain and Symptom Management,2017, 32 (2), 216- 223. 
6. Ouzouni C. and Nakakis K., An exploratory study of student nurses' empathy, Health Science Journal, 2012, 6 (3), 534- 552.

7. Parez A. et al, Empathy in the Curriculum for Patient Care, Global Journal of Health Science, 2018, 10 (4),93-99

8. Elayyan M., et al, Factors affecting empathetic patient care behaviour among medical doctors and nurses: an integrative literature review, EMHJ, 2018, 24 (3), 311-318.
9. Buyuk ET., et al, Evaluation of Empathetic Skills of Nurses Working in Oncology Units in Samsun, Turkey, International Journal of Caring Sciences, 2015, 8(1),131-139.

10. Karem M. et al, The Effect of Job Satisfaction and Organizational Commitment on Nurses' Performance, Humanities \& Social Sciences Reviews, 2019, 7(6), 332-339. 